\title{
A HISTOLOGICAL STUDY OF HUMAN FOETAL GALLBLADDER
}

\author{
Kalpana Thounaojam ${ }^{* 1}$, Ashihe Kaini Pfoze ${ }^{1}$, N. Saratchandra Singh ${ }^{2}$, Y. Ibochouba \\ Singh ${ }^{2}$. \\ ${ }^{* 1}$ Associate Professor, Department of Anatomy, Jawaharlal Nehru Institute of \\ Medical Sciences (JNIMS), Imphal, Manipur, India \\ ${ }^{2}$ Professor, Department of Anatomy, Regional Institute of Medical Sciences (RIMS), Imphal, Manipur, \\ India
}

\section{ABSTRACT}

Background: The wall of human gallbladder is composed of three layers: mucous membrane(mucosa), fibromuscular layer, adventitia (and serosa). Heterotopic tissues in the gallbladder include liver parenchymal nodules suspended in gallbladder by a mesentery, gastric mucosa and pancreatic tissue. There are not many literature on the histological development of human foetal gallbladder. The study was aimed at conducting an utmost effort on analyzing the histological layers of human foetal gallbladder at different gestational ages.

Materials and Methods: 100 fresh fetuses, of different age groups varying from 15 weeks to 40 weeks which are products of terminated pregnancy under Medical Termination of Pregnancy (MTP) Act of India,1971 and stillbirths are obtained from the Department of Obstetrics and Gynaecology, Regional Institute of Medical Sciences, Imphal. The histology of foetal gallbladder are analysed in the present study by staining the sections prepared with haematoxylin and eosin, Van Gieson's, Masson's Trichrome and Verhoeff's haematoxylin elastic tissue stains.

Result: In the present study, three histological layers of gallbladder viz., mucosa, fibromuscular layer and adventitia(and serosa) can be clearly demarcated from 18-week old foetuses onwards. In younger foetal agegroups, the lining epithelium is predominantly pseudostratified columnar with a few simple columnar epithelium. As the foetus grows older, the lining epithelium is predominated by simple columnar epithelium. In the foetal age-group of 31-40 weeks, the lining epithelium is mainly simple columnar with a few patches of pseudostratified columnar epithelium. The brush border in the lining epithelial cell of gallbladder is observed from 26 weeks of foetal age onwards. A septate gallbladder is detected.

Conclusion: This study aims to study the histological development of human foetal gallbladder. The lining epithelium of human gallbladder is simple columnar epithelium. Contrary to this finding, the present study reports that pseudostratified columnar epithelium is seen in foetal gallbladder. The brush border in the lining epithelial cell of gallbladder is observed from 26 weeks of foetal age onwards.

KEY WORDS: Gallbladder, Foetal, Histology, Development, Special Histological Stains.

Address for Correspondence: Dr Kalpana Thounaojam, Associate Professor, Anatomy Department, JNIMS, Imphal- 795005, Manipur, India. E-Mail: kalpanathounaojam@yahoo.co.in

\begin{tabular}{|c|c|c|}
\hline \multicolumn{3}{|c|}{ Access this Article online } \\
\hline \multirow{2}{*}{$\begin{array}{l}\text { Quick Response code } \\
\text { DOI: } 10.16965 / \text { ijar.2017.427 }\end{array}$} & \multicolumn{2}{|c|}{$\begin{array}{l}\text { Web site: International Journal of Anatomy and Research } \\
\text { ISSN 2321-4287 } \\
\text { www.ijmhr.org/ijar.htm }\end{array}$} \\
\hline & $\begin{array}{l}\text { Received: } 20 \text { Aug } 2017 \\
\text { Peer Review: } 20 \text { Aug } 2017 \\
\text { Revised: None }\end{array}$ & $\begin{array}{l}\text { Accepted: } 20 \text { Oct } 2017 \\
\text { Published (O): } 01 \text { Dec } 2017 \\
\text { Published (P): } 01 \text { Dec } 2017\end{array}$ \\
\hline
\end{tabular}

\section{INTRODUCTION}

The wall of human gallbladder is composed of three layers: mucous membrane(mucosa), fibromuscular layer, adventitia (and serosa).
The mucous membrane(mucosa): It is composed of epithelium and lamina propria. When empty the mucosa is thrown into many folds or rugae, making a section of it irregular, often with 
the appearance of simple glands [1].

The epithelium is a single layer of tall columnar cells with oval nuclei and a faintly eosinophilic cytoplasm. Goblet cells are absent. In histological sections, an inconspicuous striated border is observed. The cells are supported by a fine basal lamina.

At the neck of the gallbladder, occasional lymph nodules are present with a few mucous glands [1]. The epithelium of these glands is cuboidal with an unstained apical region and nucleus that is compressed at the base by accumulated secretion which is a form of mucous. Large in-pocketings of the mucosa in this region which are known as Rokitansky-Aschoff sinuses are sometimes mistaken for glands. They extend through the lamina propria and fibromuscular layer, with a lining that is continuous with the surface.

The Fibromuscular layer: External to the lamina propria is a layer of smooth muscle cells which are arranged irregularly in transverse, longitudinal and oblique bundles. In the spaces between the bundles of smooth muscle cells, there are numerous collagen and elastic fibres and occasional fibroblasts [2].

This area is the fibromuscular layer. Despite its embryological origin from a foregut derived tube, the gallbladder does not have a muscularis mucosae or submucosa [3].

The Adventitia (and serosa): External to the fibromuscular layer is a fairly dense connective tissue layer, rich in collagen and elastic fibres and contains some fibroblasts, macrophages and occasional clusters of adipose cell [2]. The part of the connective tissue layer which is in contact with the liver is known as adventitia. Here, the dense fibroconnective tissue blends in some regions with that of Glisson's capsule [1]. Elsewhere this layer is covered by peritoneum and is known as serosa.

Duct-like structures may be found on the hepatic surface of the gallbladder near its neck which can be traced in the connective tissue for a considerable distance but none open into the lumen. Some appear to connect with the bile ducts. They are called Luschka ducts and may be aberrant bile ducts. They are called Luschka ducts and may be aberrant bile ducts formed during embryonic life and persisting in the adult [2].

Heterotopic tissues in the gallbladder include:

1. Liver parenchymal nodules suspended in gallbladder by a mesentery,

2. gastric mucosa and

3. pancreatic tissue.

\section{MATERIALS AND METHODS}

100 fresh fetuses, of different age groups varying from 15 weeks to 40 weeks which are products of terminated pregnancy under Medical Termination of Pregnancy (MTP) Act of India,1971 and stillbirths are obtained from the Department of Obstetrics and Gynaecology, Regional Institute of Medical Sciences,Imphal. The fetuses are immersed in a bucket of $10 \%$ formal saline and dissected as early as possible so as to fill the lumen of the gallbladder with a fixative. The age of the fetuses are calculated from obstetrical history and crown-rump length(CRL) and gross features. The procured gallbladder specimen is rinsed in tap water so as to remove bile from it. Some tissues are fixed in neutral buffered formalin and some in $10 \%$ formal-saline. Some of these tissues are further fixed in Bouin's fluid for one day.

After proper fixation, the tissue is washed in $70 \%$ alcohol solution. The tissue is then subjected to the standard procedures of dehydration, clearing, paraffin embedding and paraffin block making.

The paraffin blocks are fixed on the block holder; trimmed and sectioned using a heavy rotary microtome. The sections are 5 micrometers thick. Ribbons of sections are mounted on egg albumin coated slides. Slides are dried and kept in an incubator overnight at room temperature. The sections are stained with haematoxylin and eosin, using Harris' haematoxylin and $1 \%$ aqueous eosin by following the standard procedure of routine haematoxylin and eosin staining.

Some of the sections are subjected to special stains for a lucid differentiation. With Weigert's iron haematoxylin for nuclear staining, Van Gieson's and Masson's Trichrome staining are done to differentiate muscle fibres, collagen fibres and fibrin. Verhoeff's haematoxylin elastic tissue staining is performed in search of elastic 
fibres and counterstained with Van Gieson's stain for muscle and collagen fibres.

The stained slides are studied under a trinocular research light microscope in 5X,10X, 40X objectives and analysed.

\section{RESULTS}

Fig. 1: 17- week old human foetal gallbladder ( $H$ \& E stain).

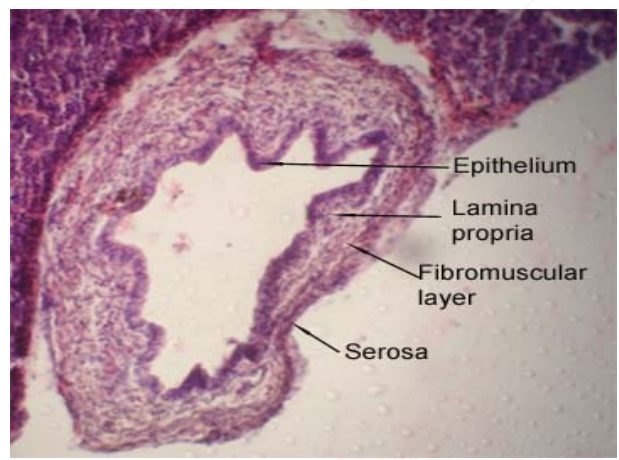

Fig. 2: 18-week old human foetal gallbladder (H \& E stain).

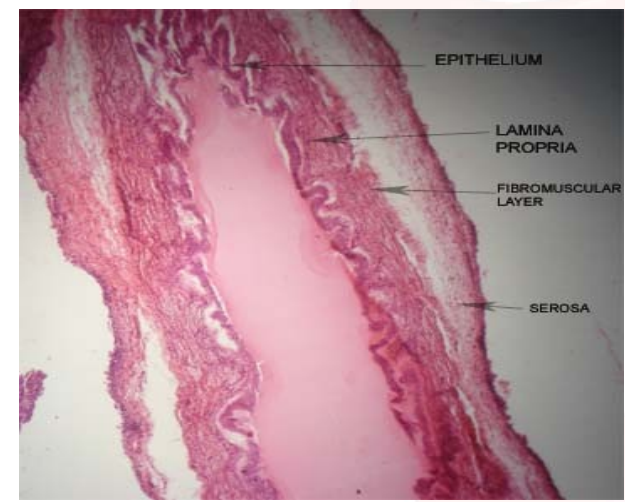

Fig. 3: 17 - week old human foetal gallbladder (H \& E stain).

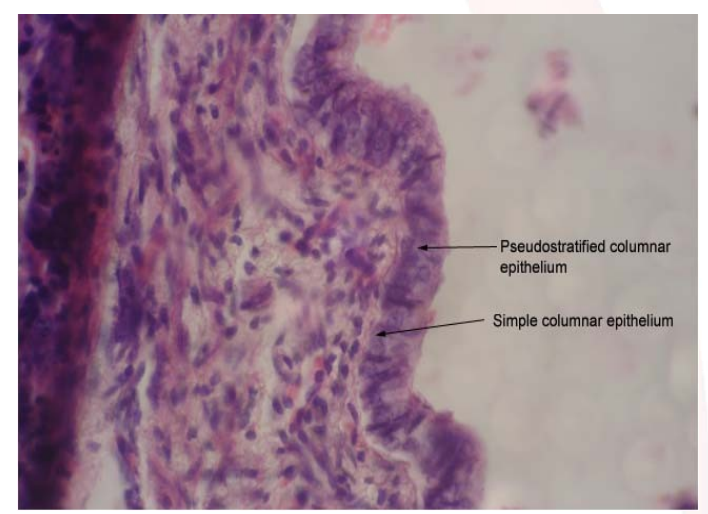

Fig. 4: 36-week old human foetal gallbladder (H \& E stain).

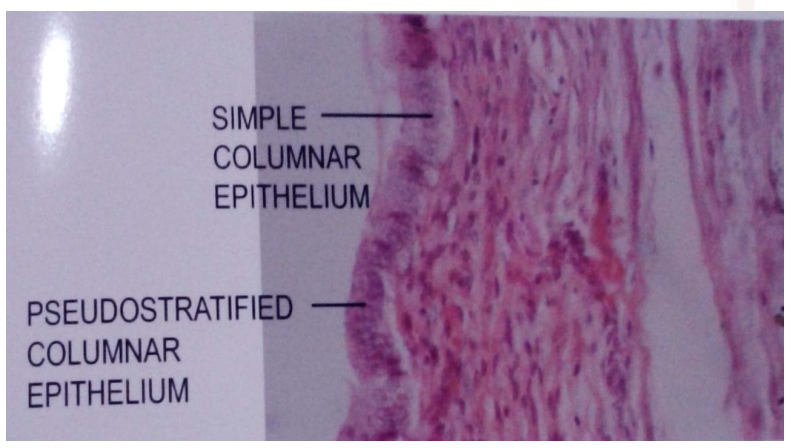

Fig. 5: 26- week old human foetal gallbladder ( $H$ \& E stain).

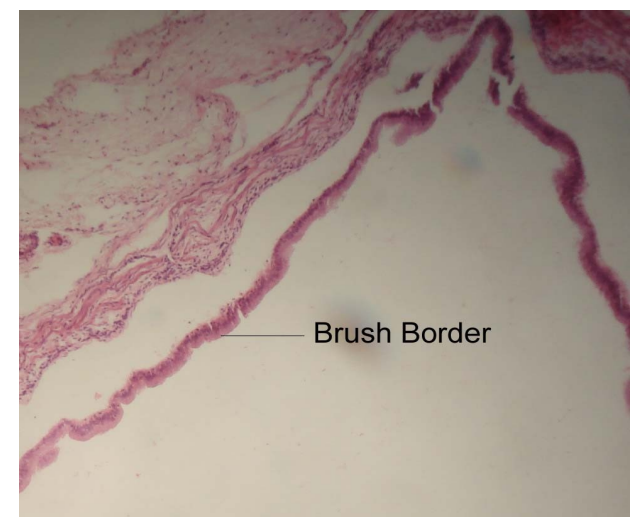

Fig. 6: 18- week old human foetal gallbladder Masson's Trichrome stain.

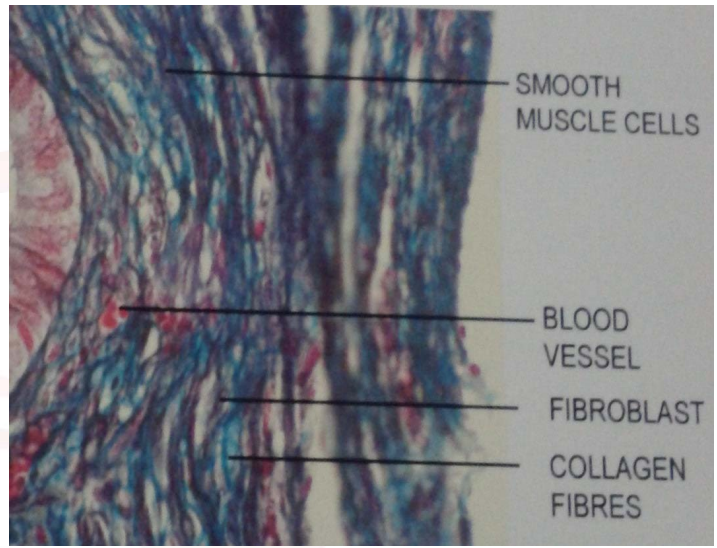

Fig. 7: 15-week old human foetal gallbladder Van Gieson's stain.

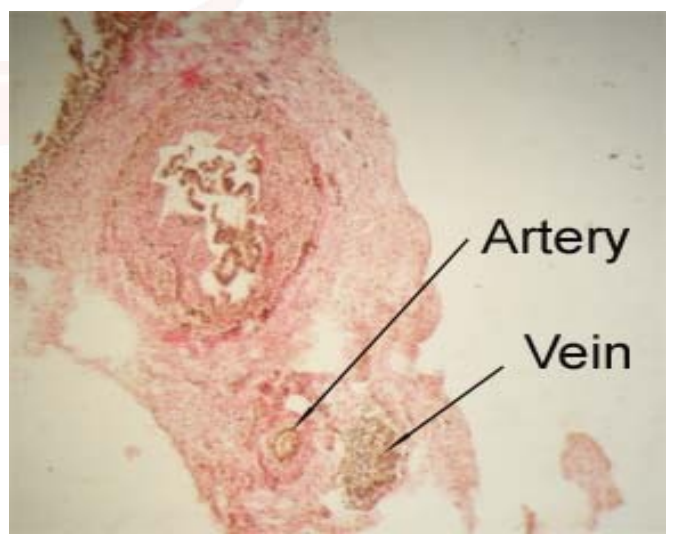

Fig. 8: 40-week old human foetal gallbladder Van Gieson's stain.

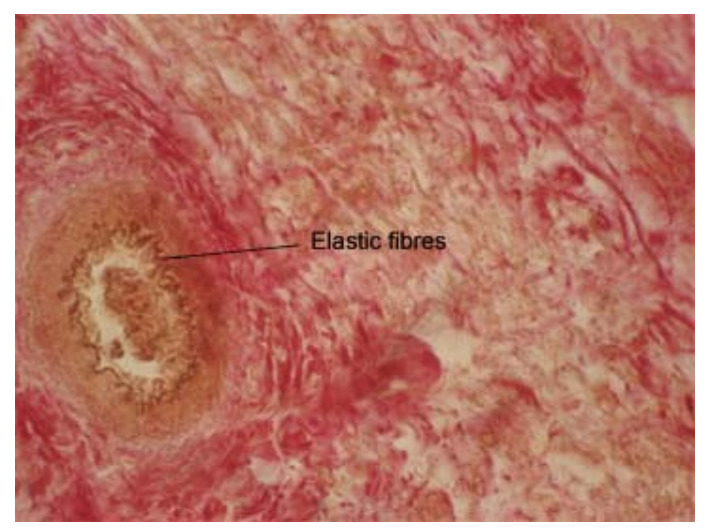


Fig. 9: Septate gallbladder (H \& E stain).

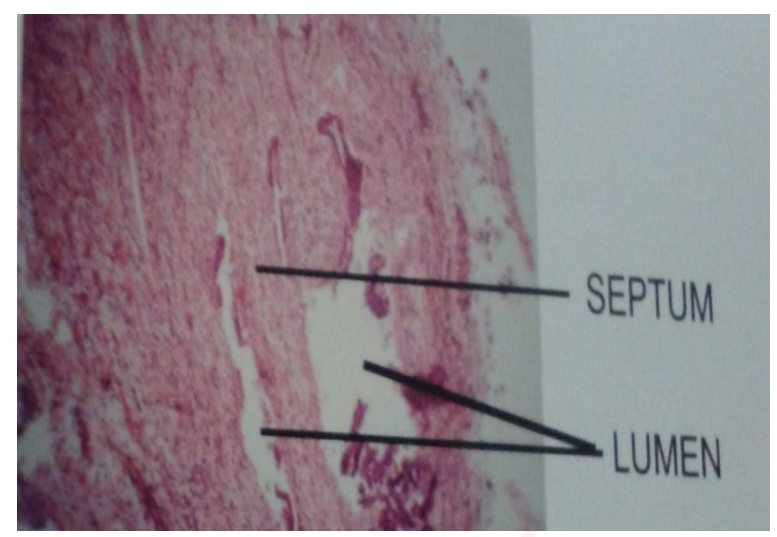

The three histological layers of gallbladder viz., mucosa, fibromuscular layer and adventitia (and serosa) cannot be distinguished upto 17 weeks of foetal age (Fig 1). From 18- week old foetus onwards, the different histological layers can be clearly demarcated (Fig 2).

In younger foetuses (15-17 weeks), the lining epithelium is mainly by pseudostratified columnar epithelium with a few simple columnar epithelium(Fig. 3). As foetus gets older, the lining epithelium is predominated by simple columnar epithelium. In the foetal age-group of 31-40 weeks, the lining epithelium is mainly simple columnar with a few patches of pseudostratified columnar epithelium(Fig 4). The brush border in the lining epithelial cell of gallbladder is observed from 26 weeks of foetal age onwards (Fig 5).

The lamina propria of the mucosa of gallbladder contains fibroblasts and collagen fibres. Elastic fibres are not visible. Small blood vessels in the lamina propria are seen from 18 weeks of foetal age(Fig 6).

The smooth muscles in the fibromuscular layer are seen to arrange in a circular manner in 15-17 week old fetuses(Fig 1). From 18 weeks of foetal age onwards, the muscles are seen to be arranged randomly(Fig 6).

By 18 weeks of foetal age, this outermost connective tissue layer (adventitia and serosa) is seen to be the thickest of all the layers(Fig 2). This layer contains plenty of collagen fibres and fibroblasts. In 15-week old foetuses, few small developing blood vessels are seen in this layer (Fig 7). Elastic fibres are observed only in the wall of bigger blood vessels of 31-40 week old fetuses(Fig 8). As foetal age advances, the developing blood vessels become larger. A septate gallbladder in a 21-week old female foetus is detected microscopically(Fig 9).

\section{DISCUSSION}

A lumen in the human foetal gallbladder is observed in $21 \mathrm{~mm}$ crown-rump (C.R.) stage and it was filled with desquamated epithelial cells without nuclei[4]. The gallbladder is occluded with epithelial cells initially, but it is later canalized because of vacuolation resulting from degeneration of these cells. In the present study, most of the debris is washed during the process of tissue processing. In microscopic study, some of the debris detected in the lumen is in agreement with the finding of the above mentioned authors.

The epithelium of the gallbladder of guinea pig during development is a pseudostratified columnar one at first and switches over to columnar thereafter[5]. In the present study also, the gallbladder is predominantly lined by pseudos tratified columnar epithelium with a few simple columnar cells in 15-20 week old foetuses. The proportion of simple columnar epithelium increases as the foetus grows older. In the foetal age- group of 31-40 weeks, the lining epithelium is mainly simple columnar with a few patchy areas of pseudostratified columnar epithelium. The free surface of the cells of lining epithelium of the gallbladder in a guineapig is covered with a thin border[6]. A few solitary cells with uniformly eosinophilic cytoplasm and a relatively compact nucleus, in addition to the tall columnar cells of the mucosa in gallbladder of rabbit are observed. The nuclei of these cells are more compact as against the generally vesicular nuclei of rest of the cells[7].The apical surface of each mucosal epithelial cell of human gallbladder is characterized by a large number of microvilli which projected into the lumen of the gallbladder[8]. The numerous short irregular microvilli which are present on the cell surface of the epithelial lining account for the unevenness of the luminal surface[9]. In the present study, the striated border in the lining epithelial cell of gallbladder is observed from 26 weeks of foetal age onwards.

The loose organization of collagen and elastic fibres in the lamina propria of gallbladder 
accounts for its property to accommodate changes in surface topography[2].

In the present study on foetus, the lamina propria is found to be rich in collagen fibres. Elastic fibres are not visible. The lamina propria of the mucosa of gallbladder is rich in fenestrated capillaries and small venules[3].

In the present study on human foetal gallbladder, small blood vessels in the lamina propria are seen from 18 weeks of foetal age. Lymphatics are present in the lamina propria[2,9]. However, the present study and another study [3] cannot detect any lymphatic vessel in this layer. The lamina propria of gallbladder contains huge amount of lymphocytes and plasma cells[3]. There are simple tubuloalveolar glands near the neck of the gallbladder in the lamina propria which extends into the muscular layer [2]. Their epithelium is cuboidal. Occasional lymph nodules are present with a few mucous glands at the neck of the gallbladder[1]. In the present study on foetal gallbladder, glands cannot be detected and there is a scattered arrangement of lymphocytes.

Despite the embryological origin of gallbladder from a foregut derived tube, it does not have a muscularis mucosae or submucosa[3].

The spaces between the bundles of smooth muscle cells in the fibromuscular layer of human gallbladder, contain numerous collagen and elastic fibres and occasional fibroblasts[2]. In the present study on human foetuses, smooth muscle, collagen and fibroblast are observed from 15-week old foetus onwards. Elastic fibres are not detected.

The earliest indication of the developing muscle cells in foetal gallbladder which can be identified by a special staining reaction is at the $30 \mathrm{~mm}$ C.R. stage[4]. The muscle fibres in muscular layer well exist in an $80 \mathrm{~mm}$ foetus(CRL?)[10]. In the present study also, the muscle fibres are well viewed in the fibromuscular layer of a 15 -week old(CRL-80mm) foetus. However, the three histological layers of gallbladder viz., mucosa, fibromuscular layer and adventitia(and serosa) cannot be distinguished till 17 weeks (CRL-105 mm) of foetal age. From 18-week old foetus onwards, the different histological layers can be clearly demarcated.
The muscle bundles in the gallbladder of guinea pig intermingle extensively and make various angles with each other and in sections do not seem to run in any preferential direction[11]. The fibres of the fibromuscular layer of human gallbladder are arranged in longitudinal, transverse and oblique orientations but do not form distinct layers. In the present study on foetal human gallbladder, the smooth muscles in the fibromuscular layer are seen to arrange in a circular manner in 15-17 week old foetuses. From 18 weeks of foetal age onwards, the muscles are seen to be arranged randomly $A$ thick layer of connective tissue is observed between the muscle coat of gallbladder and peritoneum in guinea pig and it constitutes about one-third of the thickness of the wall[11]. This layer contains large nerve bundles and the major blood vessels. The connective tissue layer of human gallbladder is rich in collagen and elastic fibres with some fibroblasts, macrophages and occasional clusters of adipose cell[2]. He further mentioned that blood vessels, nerves and lymphatics of gallbladder run in this layer and send branches through the muscular layer. In the present study, by $18^{\text {th }}$ week of foetal age the outermost connective tissue layer (adventitia and serosa) is seen to be the thickest of all the layers. This layer contains plenty of collagen and fibroblasts. Elastic fibres are observed only in the wall of the bigger blood vessels of 31-40 week old foetuses. In 15-week old foetuses, few small developing blood vessels are seen in the outer part of this layer. As the foetus grows older, the developing blood vessels become larger.

Duct-like structures, known as Luschka's duct may sometimes be observed in the connective tissue layer but none open into the lumen[2]. He presumed that Luschka's duct is probably an aberrant bile duct formed during embryonic life and persisting in the adult.

An area of heterotopic pancreas was reported in gallbladder[12]. The gallbladder is the commonest site of ectopic liver tissue[13]. Two cases of heterotopic tissue in the gallbladder i.e., gastric mucosa and liver were reported[14]. Heterotopic gastric mucosa in gallbladder resulted either in a mass, a polyp or a multiloculated gallbladder[15].

The gallbladder may be septate either trans- 
versely or longitudinally[16]. In the present study, a septate gallbladder in a 21-week old female foetus is detected microscopically.

\section{CONCLUSION}

100 fresh foetuses, 61 males and 39 females, of different age groups varying from 15 weeks to 40 weeks which are products of terminated pregnancy under Medical Termination of Pregnancy(MTP) Act of India,1971 and stillbirths have been dissected for the procurement of gallbladder specimen. The histology of foetal gallbladder are analysed in the present study by staining the sections prepared with haematoxylin and eosin, Van Gieson's, Masson's Trichrome and Verhoeff's haematoxylin elastic tissue stains.

In the present study, three histological layers of gallbladder viz., mucosa, fibromuscular layer and adventitia(and serosa) can be clearly demarcated from 18-week old foetuses onwards. In younger foetal age-groups, the lining epithelium is predominantly pseudostratified columnar with a few simple columnar epithelium. As the foetus grows older, the lining epithelium is predominated by simple columnar epithelium. In the foetal age-group of 31-40 weeks, the lining epithelium is mainly simple columnar with a few patches of pseudostratified columnar epithelium. The brush border in the lining epithelial cell of gallbladder is observed from 26 weeks of foetal age onwards. The lamina propria of the mucosa of gallbladder contains fibroblasts and collagen fibres. Blood vessels in this layer are observed from 18 weeks of foetal age. The smooth muscles in the fibromuscular layer of gallbladder are seen to arrange in a circular manner in 15-17 week old foetuses. From 18 week-old foetuses onwards, the muscles are seen to arrange randomly. By 18 weeks of foetal age, this outermost connective tissue layer(adventitia and serosa) is seen to be the thickest of all the layers. This layer contains collagen fibres and fibroblasts. In this layer, elastic fibres are observed only in the wall of bigger blood vessels of 31-40 week old foetuses. In 15-week old foetuses, few small developing blood vessels are seen in this layer. As age advances, the developing blood vessels become larger. A septate gallbladder is detected.

\section{Conflicts of Interests: None}

\section{REFERENCES}

[1]. Leeson CR, Leeson TS, Paparo AA. The Digestive System.Text/ Atlas of Histology. $6^{\text {th }}$ Edition. Philadelphia: W.B. Saunders, 1988;394-502.

[2]. Fawcett DW. The liver and Gallbladder. A textbook of Histology. $12^{\text {th }}$ Edition. New York: Chapman and Hall,1994;652-688.

[3]. Ross MH, Kaye GI, Pawlina W. Gallbladder and Pancreas. A Text and Atlas in Liver. $4^{\text {th }}$ Edition. Philadelphia: Lippincott Williams and Wilkins . 2003;532567.

[4]. Jit I. The development of the unstriped musculature of the gallbladder and the cystic duct in J. Anat.Soc.India.1959;8(1):15-20.

[5]. Schiebler TH, Lang K, Wahlin T. The development of the guinea pig gallbladder epithelial cells in I. Light microscopical and histochemical investigations. Histochemistry 1975;45(3):177-190.

[6]. Yamada K. Morphological and histochemical aspects of secretion in the gallbladder epithelium of the guinea pig in Anat. Rec. 1962;144(1):117-127.

[7]. Chowdhary DS, Jain KK. Some observations on gallbladder mucosa in vertebrates in J. Anat.Soc.India 1969;18(1):1-3.

[8]. Chapman GB, Chiarodo AJ, Coffey RJ,Weineke K. The fine structure of mucosal epithelial cells of a pathological human gallbladder in Anat,Rec. 1966;154(3) :579-615.

[9]. Young B ,Heath JW. Liver and Pancreas. Wheater's functional histology: A Text and colour Atlas $4^{\text {th }}$ Edition. London: Churchill Livingstone, 2000;274285.

[10]. Lee $H$, Halpert B. The gallbladder and the extrahepatic biliary passage in late embryonic and early fetal life in Anat. Rec. 1932;54:29-43.

[11]. Cai WQ ,Gabella G. The musculature of the gallbladder and biliary pathways in the guinea pig in J.Anat. 1983;136(2):237-250.

[12]. Shiwani MH, Gosling J. Heterotopic pancreas of the gallbladder associated with chronic cholecystitis in JOP 2008;9(1):30-2.

[13]. Griniatsos J, Riaz AA, Isla AM. Two cases of ectopic liver attached to the gallbladder wall in HPB (Oxford) 2002;4(4):191-194.

[14]. Boyle L, Gallivan MV, Chun B ,Lack EE. Heterotopia of gastric mucosa and liver involving the gallbladder. Report of two cases with literature review in Arch Pathol Lab Med. 1992;116(2):138-42.

[15]. Vallera DU, Dawson PJ ,Path FR. Gastric heterotopias in the gallbladder. Case report and review of literature. Pathol Res Pract. 1992;188(1-2):49-52.

[16]. Decker GAG, du Plessis DJ. The Liver and biliary system. Lee McGregor's Synopsis of Surgical Anatomy. $12^{\text {th }}$ Edition. Bristol: John Wright \& Sons Ltd., 1986;78-102. 